\title{
Positive Newborn Screening for Cystic Fibrosis, What to Do Next?
}

\author{
Prawin Kumar $^{1} \cdot$ Jagdish Prasad Goyal ${ }^{1}$
}

Received: 6 June 2019 / Accepted: 8 July 2019 / Published online: 19 July 2019

(C) Dr. K C Chaudhuri Foundation 2019

To the Editor: Recently, we have encountered two newborns babies with raised immunoreactive trypsinogen (IRT) assay. In India, with the widespread use of newborn screening (NBS), an increasing number of babies with raised IRT are being recognized. These babies are often mislabeled as cystic fibrosis (CF) without any further workup, which produces unnecessary stress among parents.

Traditionally, the diagnosis of $\mathrm{CF}$ is made by recognition of characteristic signs and symptoms. However, with the widespread use of CF NBS in many western countries, early diagnosis of $\mathrm{CF}$ is possible even in the asymptomatic stage, and now it has became the most common modality of new $\mathrm{CF}$ diagnosis [1]. In the west, there are two types of CF NBS protocols in practice viz. IRT/DNA and IRT/IRT/DNA. In either protocol, the first step is IRT assay, which remains persistently elevated for weeks to months in CF children [2]. Although, raised IRT in the first week of life is a sensitive marker but not specific for the diagnosis of CF. IRT may be falsely elevated in many other conditions viz. neonatal stress, hypoglycemia, meconium contamination, and congenital infection or even in the healthy newborn [3]. The next step is either to repeat the IRT assay after two weeks or directly proceed for the common cystic fibrosis transmembrane conductance regulator (CFTR) mutations analysis [2, 4]. Whatever the initial protocol one follows, sweat chloride is mandatory for the establishment of CF diagnosis in babies with positive CF NBS [5].

In India, there is no such guideline for CF NBS and also testing for CFTR mutations is limited by its cost and availability. In our cases, we first repeated the IRT assay, which remained persistently elevated in the first baby while it fell within the normal range in the second baby. Furthermore, sweat chloride test was performed in both the babies, which was raised in the first baby on two occasions (79 and $90 \mathrm{mEq} / \mathrm{L}$

Prawin Kumar

drprawin484@gmail.com

1 Department of Pediatrics, All India Institute of Medical Sciences, Jodhpur, Rajasthan 342005, India respectivley) and hence a diagnosis of $\mathrm{CF}$ was labeled to him; however, it was within normal range $(26 \mathrm{mEq} / \mathrm{L})$ in the second baby, and he was kept on clinical follow-up. The first baby was male; he developed pneumonia (Staphylococcus aureus) at two months of age and subsequently also had steatorrhea. In the first year of follow up, he required multiple hospitalizations for recurrent pneumonia, failure to thrive, and electrolyte imbalance (pseudo-Bartter syndrome). The second baby was also male and was growing well, gaining adequate weight and did not develop any significant illness in the first year of life.

In conclusion, raised IRT is not a diagnostic test for CF. If raised IRT level is detected, it may be wiser first to repeat the IRT assay after two weeks and if it remains persistently elevated then the baby should be investigated for sweat chloride test and/or CFTR mutational analysis. It must be emphasized that clinical phenotype should also be taken into account before establishing the final diagnosis of $\mathrm{CF}$.

\section{Compliance with Ethical Standards}

Conflict of Interest None.

\section{References}

1. Wallis C. Diagnosis and presentation of cystic fibrosis. In: Wilmott RW, Deterding R, Li A, et al., editors. Kendig's Disorders of the Respiratory Tract in Children, 9th ed. Philadelphia: Elsevier; 2019. p. 769-76.

2. Farrell PM, White TB, Howenstine MS, et al. Diagnosis of cystic fibrosis in screened populations. J Pediatr. 2017;181:S33-44.e2.

3. Massie J, Curnow L, Tzanakos N, Francis I, Robertson CF. Markedly elevated neonatal immunoreactive trypsinogen levels in the absence of cystic fibrosis gene mutations is not an indication for further testing. Arch Dis Child. 2006;91:222-5.

4. Farrell PM, White TB, Ren CL, et al. Diagnosis of cystic fibrosis: consensus guidelines from the Cystic Fibrosis Foundation. J Pediatr. 2017;181S:S4-15.e1.

5. Smyth AR, Bell SC, Bojcin S, et al. European Cystic Fibrosis Society standards of care: best practice guidelines. J Cyst Fibros. 2014;13:S23-42.

Publisher's Note Springer Nature remains neutral with regard to jurisdictional claims in published maps and institutional affiliations. 